\title{
Baseline CD44v6-positive circulating tumor cells to predict first- line treatment failure in patients with metastatic colorectal cancer
}

\author{
Chiara Nicolazzo ${ }^{1}$, Flavia Loreni ${ }^{1}$, Salvatore Caponnetto ${ }^{2}$, Valentina Magri ${ }^{2}$, \\ Anna Rita Vestri ${ }^{3}$, Rita Zamarchi ${ }^{4}$, Angela Gradilone ${ }^{1}$, Antonella Facchinetti ${ }^{4,5}$, \\ Elisabetta Rossi ${ }^{4,5}$, Enrico Cortesi ${ }^{2}$ and Paola Gazzaniga ${ }^{1}$ \\ ${ }^{1}$ Department of Molecular Medicine, Liquid Biopsy Unit, Sapienza University of Rome, Rome, Italy \\ ${ }^{2}$ Department of Radiological, Oncological and Pathological Sciences, Sapienza University of Rome, Rome, Italy \\ ${ }^{3}$ Department of Public Health and Infectious Diseases, Sapienza University of Rome, Rome, Italy \\ ${ }^{4}$ Veneto Institute of Oncology IOV-IRCCS, Padua, Italy \\ ${ }^{5}$ Department of Surgery, Oncology and Gastroenterology, University of Padova, Italy \\ Correspondence to: Chiara Nicolazzo, email: chiara.nicolazzo@uniromal.it \\ Keywords: cancer stem cells; CD44v6; circulating tumor cells; colorectal cancer; CellSearch ${ }^{\circledR}$ \\ Received: July 22, 2020 \\ Accepted: October 17, 2020 \\ Published: November 10, 2020
}

Copyright: ( 2020 Nicolazzo et al. This is an open access article distributed under the terms of the Creative Commons Attribution License (CC BY 3.0), which permits unrestricted use, distribution, and reproduction in any medium, provided the original author and source are credited.

\section{ABSTRACT}

CD44v6, the CD44 isoform mostly involved in cancer cell migration and invasion, has been identified as a functional biomarker and therapeutic target in colon cancer stem cells. We here provide evidence that baseline CD44v6-positive CTC predict treatment failure in patients with metastatic colorectal cancer undergoing first-line chemotherapy. We suggest that CD44v6-positive CTC can be used to early detect intrinsic drug resistance in this cancer type.

\section{INTRODUCTION}

Cellular heterogeneity within circulating tumor cells (CTC) has been widely described and blood-monitoring studies in tumor patients have revealed the presence of CTC able to survive chemotherapy and to generate metastases after xenotransplantation in immunodeficient mice [1]. Therefore, the identification of drug resistant CTC in the entire pool of tumor cells disseminated in the bloodstream would, at least theoretically, provide a unifying hypothesis on CTC and cancer stem cells (CSC). Nevertheless, the relationship between circulating tumor cells and cancer stem cells is complex and currently under debate and the discovery of specific markers is an aim hard to be reached [2]. CD44v6, the CD44 isoform mostly involved in cancer cell migration and invasion, has been identified as a functional biomarker of stemness and therapeutic target in colorectal cancer (CRC) tissues [3]. CD44v6 expression has been reported in all colorectal cancer stem cells, and it is required for their migration and generation of metastatic tumors [4]. This concept is supported by experimental mouse models, which demonstrated that tumorigenic activity is confined in the CD44v6 population [3].

Functional studies have recently demonstrated that patient-derived colorectal CTC bear all the functional attributes of CSC and are strongly enriched for CD44v6 expression [5]. From a clinical perspective, CD44v6 is a negative prognostic factor in $\mathrm{CRC}$, being 5-years survival rate of patients with CD44v6-positive and -negative tumors $52.78 \%$ and $80.95 \%$ respectively [6]. Furthermore, CD44v6 contributes to chemoresistance as demonstrated by in vitro studies showing that CD44v6-overexpressing cells are resistant to 5 -fluorouracil (5-FU) or oxaliplatin by activating PI3K/Akt, mitogen-activated protein kinase/extracellular-signal-regulated kinase (MAPK/ ERK), epithelial-mesenchymal transition (EMT), and autophagy-related signaling pathways [7-10]. Whether CD44v6 might be used to reflect the burden of circulating drug-resistant cells before starting therapy remains an unanswered question. We conducted a pilot study in order to evaluate the prognostic significance of baseline CD44v6-positive CTC in metastatic colorectal cancer patients candidate to first-line treatment.

\section{RESULTS}

In order to assess the CD44v6 status in CTC from metastatic colorectal cancer (mCRC) patients, blood samples from 40 patients were analyzed through CellSearch $^{\circledR}$ system before starting first-line therapy. 
Baseline characteristics of enrolled patients are listed in Table 1. Tumor response was measured 12 months after start of treatment using the revised Response Evaluation Criteria in Solid Tumors (RECIST) v1.1. Patients with stable disease (SD), partial response (PR) or complete response $(\mathrm{CR})$ were regarded as responders, whilst patients with progressive disease (PD) as non-responders. Tumor responses (SD, PR or CR) were observed in 21 out of 40 patients $(52.5 \%)$ with $1 \mathrm{CR}, 10 \mathrm{PR}$ and $10 \mathrm{SD}$, whereas no response (PD) was observed in 19 patients $(47.5 \%)$. The study flow diagram is shown in Figure 1. Based on the distribution of CTC, patients were dichotomized into two groups, as follows: negative (0 CTC) and positive ( $\geq$ 1 CTC). In regard to CD44v6 status, a threshold of $\geq 1$ CTC expressing the antigen was applied to consider a sample as positive. Patients were 20 women and 20 men. No difference was found between mean age (female yrs $64.1 \pm 7.7$, median 65; men $62.8 \pm 10.1$, median 63 ) There was a statistical difference between CTC and sex (Fisher's exact test $p<0.001)$. CTC-positive patients were 18 women (72\%) and 7 men (28\%), while CTC-negative were 2 women $(13.3 \%)$ and 13 men $(86.7 \%)$. No statistical difference was observed between CD44v6 expression and sex (4 men and 10 women in CD44v6-positive group vs 3 men and 8 women in CD44v6-negative group).

\section{Circulating tumor cells and CD44v6 status}

CTC were detected in 25 out of the $40(62.5 \%)$ patients evaluated, whilst no CTC were found in 15 patients (37.5\%). Among the 25 patients with CTC, 4 (16\%) had 1 CTC, 5 (20\%) had 2 CTC, 4 (16\%) had 3 CTC, $3(12 \%)$ had 4 CTC, 2 (8\%) had 5 CTC, 1 (4\%) had 6 CTC, 2 (8\%) had 7 CTC, 2 (8\%) had 8 CTC, 1 (4\%) had 10 CTC and 1 (4\%) had 11 CTC (range 1-11, median number 3). CD44v6 expression was found in 14 out of the 25 (56\%) CTC-positive patients, whereas no CD44v6 expression was detected in 11 out of 25 (44\%) patients. In the group of CD44v6-positive patients, CD44v6 expression was found in all CTC (100\%) in 3 out of 14 patients, in $50 \%$ of CTC in 3 out of 14 and in more than half of CTC $(\geq 50 \%)$ in 8 out of 14 (range $1-8$, median number 4). Figure 2 shows 6 CD44v6-expressing CTC isolated from one patient. CTC numbers and related CD44v6 status for each patient are listed in Supplementary Table 1.

\section{Circulating tumor cells according to treatment regimen}

Among the 33 patients for whom RAS status of the primary tumor was available, 16 patients received chemotherapy plus antiangiogenic drugs while 17 received chemotherapy plus epidermal growth factor receptor (EGFR) inhibitors (see Supplementary Table 1). CTC were found more frequently in patients with RAS mutant primary tumors compared to wild-type ( $94 \%$ versus $41 \%$ respectively). Accordingly, CD44v6-positive CTC were found in 73\% of patients who received antiangiogenic drugs, compared to $14 \%$ of patients candidate to receive EGFR inhibitors. CTC were found in $3 / 7$ (42\%) patients who did not receive targeted therapies; $2 / 3$ (67\%) expressed CD44v6.

\section{Circulating tumor cells and clinical response}

In the group of CTC-positive patients we had 16 out of $25(64 \%)$ patients with progression of disease at 12 months, 5 out of 25 (20\%) with stable disease, 3 out of $25(12 \%)$ with partial response, while 1 out of $25(4 \%)$ had a complete response. In the group of CTC-negative patients we had PD in 3 out of $15(20 \%)$ patients, SD in 6 out of $15(40 \%)$, PR in 6 out of $15(40 \%)$ and no patients had CR $(0 \%)$. We found a statistical difference between progressive disease and CTC (Fisher's exact test $p=0.01$; PHI index $=0.427 p=0.007)$. The association between CTC and clinical response is shown in Table 2.

\section{Relation of CD44v6 status in circulating tumor cells to clinical response}

All patients who presented with at least 1 CTC expressing CD44v6 had progression of disease at 12 months $(100 \%)$, whilst no SD, PR or CR were observed. On the other hand, in the group of CD44v6-negative patients, we had PD in 2 out of 11 (18\%) patients, and SD in 5 out of $11(45 \%)$, PR in 3 out of $11(27 \%)$ and CR in 1 out of $11(9 \%)$. The association between progressive disease and CD44v6 was found statistically significant (Fisher's exact test $p<0.0001$; PHI index $=0.846 p<$ 0.00001). In Table 2 the association between CD44v6 expression and clinical response is shown.

\section{DISCUSSION}

Several studies have provided evidence that CTC represent a heterogeneous pool of tumor cells, and that a subpopulation showing an intermediate phenotype between epithelial and mesenchymal might express stem-like markers. Consistently CTC expressing putative biomarkers of stemness have been associated to therapy failure and disease progression [11]. CD44, a widely expressed adhesion molecule, contributes to cell-cell and cell-matrix adhesion, cell growth and differentiation, and is highly expressed on stem cells [3]. It exists in numerous variant isoforms among which CD44v6 has been recognized as a marker for colon cancer CSC. There is growing evidence that CD44v6 is associated with an increased metastatic risk, drug resistance and a lower survival rate in different cancer types, nevertheless evidence about the prognostic significance of CD44v6-positive CTC is lacking to date. This pilot study was aimed to assess the association between CD44v6 and response to first-line regimen in metastatic 


\begin{tabular}{|c|c|}
\hline Characteristics & No. of patients $(n=40)$ \\
\hline \multicolumn{2}{|l|}{ Sex } \\
\hline Male & $20(50 \%)$ \\
\hline Female & $20(50 \%)$ \\
\hline \multicolumn{2}{|l|}{ Primary tumor location } \\
\hline Right & $10(25 \%)$ \\
\hline Left & $19(47.5 \%)$ \\
\hline Rectum & $11(27.5 \%)$ \\
\hline \multicolumn{2}{|l|}{ Stage of disease } \\
\hline Metastatic & $40(100 \%)$ \\
\hline \multicolumn{2}{|l|}{ Metastatic site } \\
\hline Liver & $40(100 \%)$ \\
\hline \multicolumn{2}{|c|}{ RAS/BRAF status (tumor tissue) } \\
\hline Wild type & $17(42.5 \%)$ \\
\hline Mutant & $16(40 \%)$ \\
\hline unknown & $7(17.5 \%)$ \\
\hline \multicolumn{2}{|l|}{ Line of therapy } \\
\hline 1 st & $40(100 \%)$ \\
\hline \multicolumn{2}{|l|}{ Therapy } \\
\hline FOLFOXIRI /bevacizumab & $7(17.5 \%)$ \\
\hline FOLFIRI/bevacizumab & $1(2.5 \%)$ \\
\hline FOLFOX/bevacizumab & $8(20 \%)$ \\
\hline FOLFIRI/EGFRi & $14(35 \%)$ \\
\hline FOLFOXIRI/EGFRi & $3(7.5 \%)$ \\
\hline FOLFOX & $3(7.5 \%)$ \\
\hline FOLFIRI & $1(2.5 \%)$ \\
\hline XELOX & $1(2.5 \%)$ \\
\hline XELIRI & $2(5 \%)$ \\
\hline $\mathrm{CTC}=\mathbf{0}$ & $15(37.5 \%)$ \\
\hline CTC $\geq 1$ & $25(62.5 \%)$ \\
\hline CD44v6-positive & $14(35 \%)$ \\
\hline CD44v6-negative & $11(27.5 \%)$ \\
\hline
\end{tabular}

colorectal cancer patients, evaluated according to RECIST criteria. At this regard, a follow up period of 12 months was considered appropriate, since first-line treatment with both doublets, FOLFIRI or FOLFOX, produces a median progression-free survival (PFS) of 8.5-9 months in most randomized phase III trials $[12,13]$. As far as we know this is the first demonstration that baseline CD44v6-positive CTC are associated to treatment failure, suggesting that CD44v6-positive subpopulations may reflect a biomarker of intrinsic resistance to treatment. Despite the small sample size, we observed that the characterization of CD44v6 in CTC at baseline is more significantly associated to treatment failure than CTC enumeration. In this respect, the choice to assess the prognostic significance of CTC irrespective of the standard cut-off ( $3 \mathrm{CTC} / 7.5 \mathrm{~mL}$ ) was based on our previous demonstration that the presence of at least 1 CTC at baseline count is more predictive for poor prognosis in mCRC patients [14].

Whether CD44v6 expression in CTC might be attributed to the acquisition of stem-like properties is still an unanswered question. Recently, Fumagalli et al. demonstrated in a colorectal cancer model that CSC are not present in circulation, and that non-CSC are in fact the major seeding cells, while conversion to CSC at the metastatic site is required for efficient metastatic outgrowth [15].

Nevertheless, our results are in line with those described by other authors, who found CD44v6 expression 
Table 2: Clinical response and CTC number or CD44v6 status at baseline

\begin{tabular}{lcccccccc}
\hline & \multicolumn{1}{c}{ Patients } \\
\cline { 2 - 9 } & \multicolumn{2}{c}{ CTC+ } & CTC- & \multicolumn{2}{c}{ CD44v6+ } & \multicolumn{2}{c}{ CD44v6- } \\
\hline Response & N & \% & N & \% & N & \% & N & \% \\
\hline PD & 16 & 64 & 3 & 20 & 14 & 100 & 2 & 18 \\
PR & 3 & 12 & 6 & 40 & 0 & 0 & 3 & 27 \\
SD & 5 & 20 & 6 & 40 & 0 & 0 & 5 & 45 \\
CR & 1 & 4 & 0 & 0 & 0 & 0 & 1 & 9 \\
\hline
\end{tabular}

Abbreviations: N, number; PD, progressive disease; PR, partial response; $\mathrm{SD}$, stable disease; $\mathrm{CR}$, complete response; $\mathrm{CTC}$, circulating tumor cell; +, positive; -, negative.

in CTC cultured lines and demonstrated the existence of patient-derived colorectal CTC that bear all the functional attributes of CSC $[16,17]$. Although these models are promising in drug-screening and resistance mechanism research, they are technically challenging, time-consuming and costly, thus not suitable for routine clinical practice. In addition, the rate of CTC in colon cancer patients is low, making not easy to establish CTC cultures in this tumor type.

The identification of CD44v6 in CTC might represent a useful tool for better evaluation of tumor response. Since CD44v6 acts as a co-receptor for vascular endothelial growth factor (VEGF) [18], the detection of CD44v6-positive CTC might be used to serially monitor the emergence of drug resistance in course of antiangiogenic therapy. At this regard, we observed a higher frequency of CTC-positive patients in the group of RAS mutant compared to RAS wild-type, and CD44v6-positive $\mathrm{CTC}$ were also more frequent in patients candidate to receive antiangiogenic drugs compared to those who were treated with EGFR inhibitors. The treatment failure prediction of CD44v6-positive circulating tumor cells seemed independent from the first-line treatment regimen, although the sample size did not allow drawing significant conclusions. Furthermore, the activity of immune checkpoint inhibitors in microsatellite instability (MSI)-high CRC might be reduced in CD44v6-positive tumors, due to the interference of Fas signaling by CD44 variant isoforms [19]; consequently, a further application of CD44v6-positive CTC might be immunotherapy monitoring. In addition, the CD44v6 test in CTC might be used to identify high-risk stage II/III patients who could benefit from additional systemic therapies after primary tumor surgery.

This work has several limitations. First, further studies with a larger number of patients are required to understand the statistical significance of these findings as well as to clarify whether CD44v6 might really reflect the

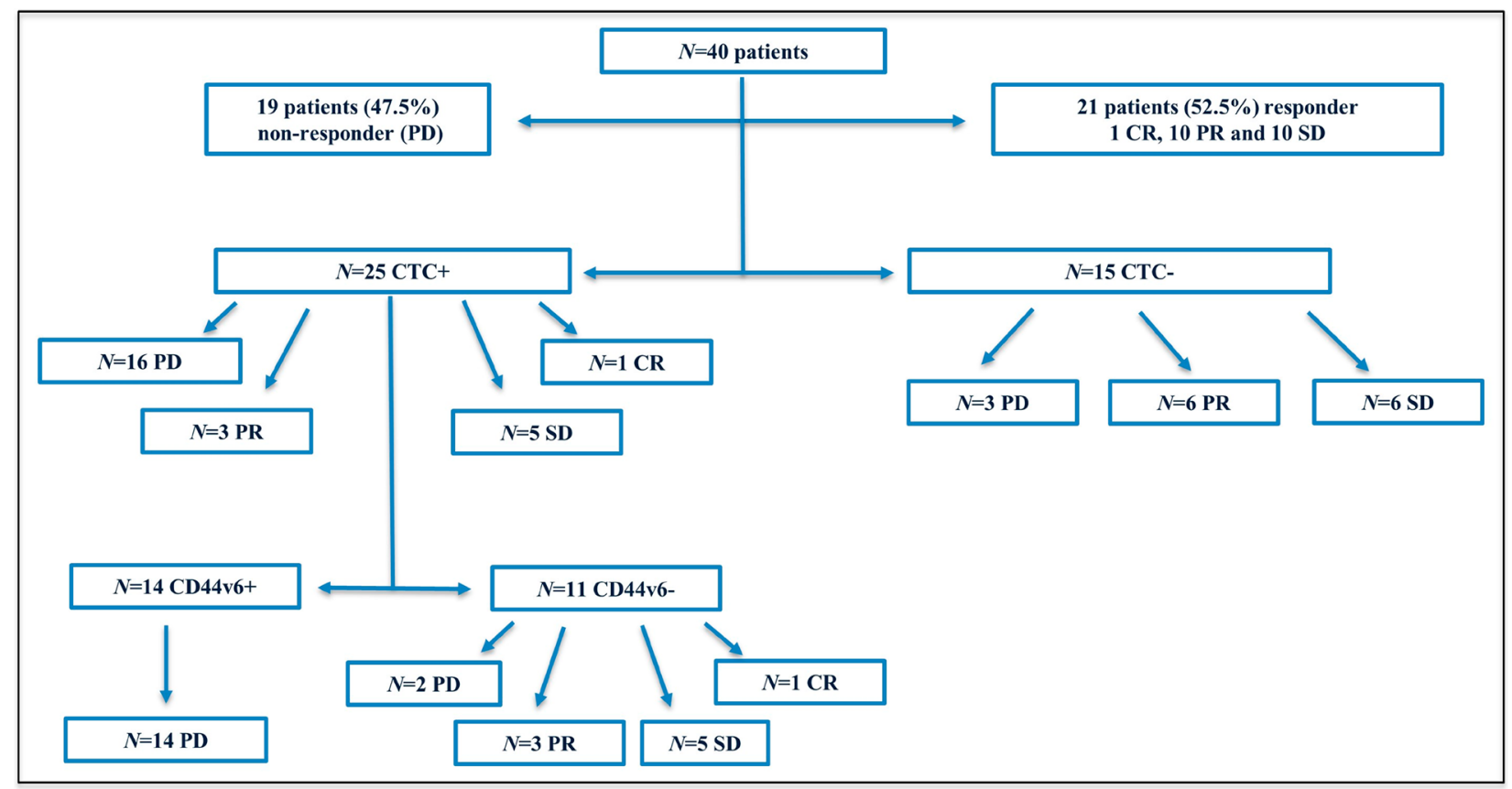

Figure 1: Flow diagram of the study. Abbreviations: N, number; PD, progressive disease; CR, complete response; PR, partial response; SD, stable disease; $\mathrm{CTC}$, circulating tumor cells; +, positive; -, negative. 
burden of CRC stem cells in this tumor type. Second, since treatment regimen was inconsistent among patients, a future study enrolling a larger patients' population is planned to clarify whether CD44v6 might reflect an intrinsic resistance to most conventional chemotherapies/targeted therapies or to specific anticancer drugs. Third, despite the aim of this study was to correlate CD44v6-positive CTC and response to first-line regimen, a longer follow up time, which is in course, will allow us to correlate CD44v-positive CTC with PFS and overall survival (OS). Further studies are required to confirm whether this test might improve the early identification of metastatic colorectal cancer patients who are expected to poorly respond to first-line treatments.

In conclusion, CD44v6 seems to act as a drug resistance signature in $\mathrm{CTC}$ from metastatic colorectal cancer patients, being associated to poor tumor response to different first-line treatments. Despite the small number of patients, which is consistent with a pilot study, its expression in CTC at baseline seems to reflect a wide mechanism of drug intrinsic resistance, which might be suggestive for stem-like properties. We speculate that the detection of CD44v6-positive CTC might represent an additional prognostic tool useful to early identify patients with an expected poor response to first-line regimens.

\section{MATERIALS AND METHODS}

\section{Experimental design}

We conducted a pilot study in order to evaluate the utility of baseline (pre-treatment) assessment of CD44v6 status in CTC in predicting clinical outcomes in $\mathrm{mCRC}$ patients. The first step was developing a CD44v6-specific assay by integrating CellSearch ${ }^{\circledR}$ system (Menarini Silicon Biosystems, Castel Maggiore, Bo, Italy) with a monoclonal antibody direct against the stemness marker. After that, a blood sample from each patient enrolled in the study was collected before starting the first-line treatment and used for analysis of CTC. Response to treatment was based on imaging documentation, mostly CT scans, and coded according to RECIST version 1.1.

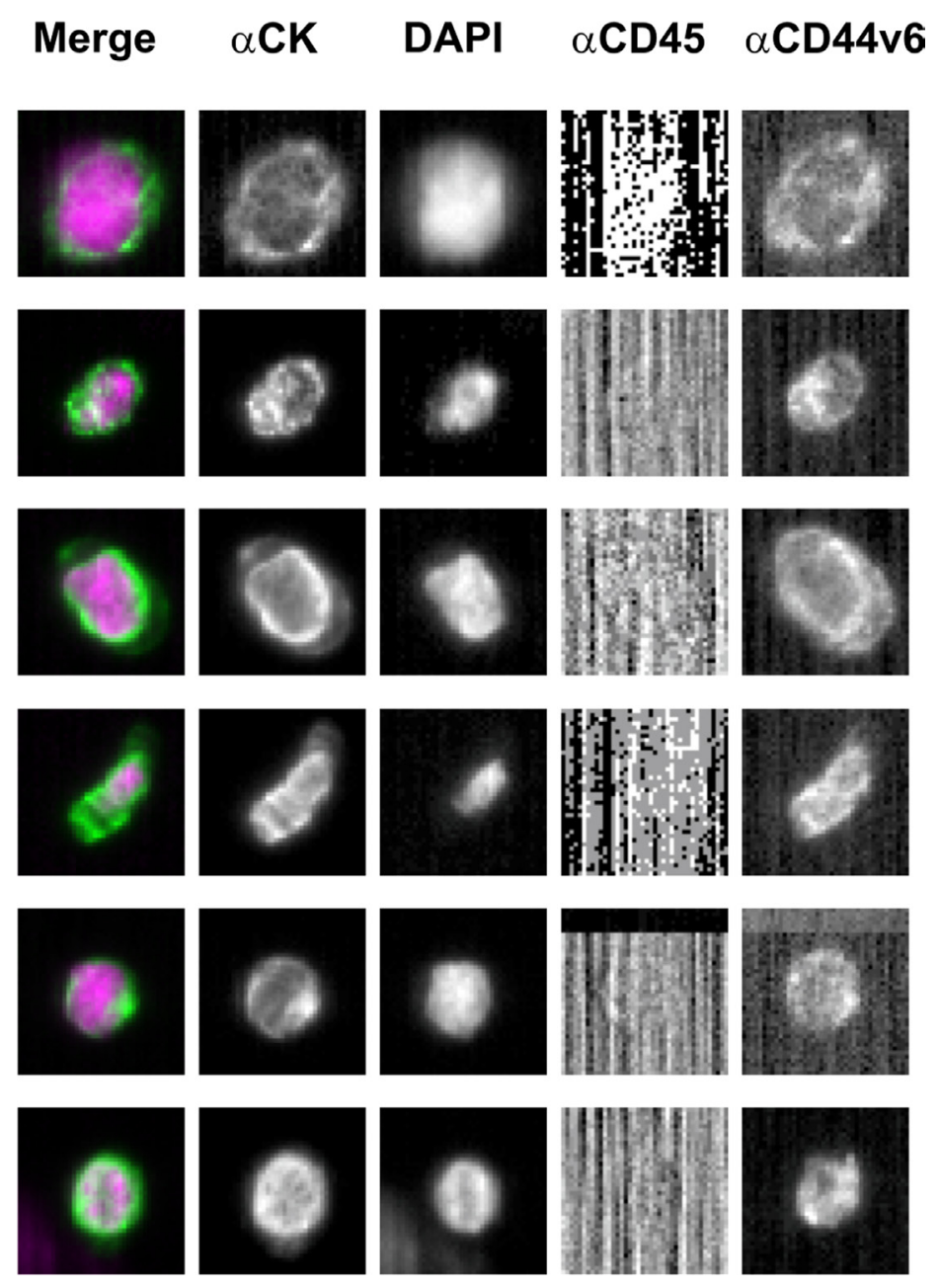

Figure 2: Representative images of CD44v6-positive circulating tumor cells isolated from one metastatic colorectal patient. Abbreviations: CK-FLU, cytokeratin fluorescein-conjugated (green); DAPI, 4',6-diamidino-2-phenylindole (violet); APC, allophycocyanin; PE, phycoerythrin. 


\section{Patients and healthy volunteers}

Forty patients with $\mathrm{mCRC}$ were enrolled at baseline before start of first-line treatment. The protocol had been approved by Ethical Committee of Policlinico Umberto I of Rome (protocol n. 668/09, July 09, 2009; amended protocol 179/16, March 01, 2016). Blood from healthy volunteers was taken for spiking experiments. Informed consent was obtained from all participants included in the study. Eligible patients had metastatic colorectal cancer surgically unresectable and/or metastatic (stage IV). Other inclusion criteria were: over 18 years of age; ECOG Performance Status $\leq 2$; adequate bone marrow, liver and renal function. Systemic anticancer therapy was triplet (FOLFOXIRI) or doublet (FOLFOX or FOLFIRI) backbone chemotherapy with bevacizumab or EGFR inhibitors upon the decision made by the physician. Patients were monitored for 12 months.

\section{Circulating tumor cells analysis}

A volume of $7.5 \mathrm{~mL}$ of peripheral blood from each participant was collected into CellSave Preservative tubes (Menarini Silicon Biosystems), kept at room temperature and processed through CellSearch ${ }^{\circledR}$ system within 72 h. To this end, the CellSearch ${ }^{\circledR}$ CXC kit (Menarini Silicon Biosystems) was employed and anti-human CD44v6 Phycoerythrin (PE)-conjugated antibody (clone FAB3660P; R\&D Systems, Minneapolis, USA) was added into user-defined marker channel at a concentration of $0.02 \mu \mathrm{g} / \mathrm{mL}$. Briefly, after epithelial cellular adhesion molecule (EpCAM)-based immunoselection, the enriched cells were labelled with fluorescent dyes for the detection of nucleus, cytokeratins (CK) 8, 18, and 19, CD44v6 and CD45. Immunofluorescence image were finally analyzed through CellSearch ${ }^{\circledR}$ Analyzer II. An event was considered as a CTC when having round to oval morphology, a visible nucleus, positive staining for $\mathrm{CK}$, negative staining for $\mathrm{CD} 45$, and negative or positive staining for CD44v6.

\section{Development and optimization of CTC assay specific for CD44v6 expression}

In order to optimize the antibody concentration and the Exposure Time of the image scanning [20-24], spiking experiments in blood samples from healthy volunteers were performed using a cell line known to express CD44v6. To this purpose, MDA-MB 231 cell line exhibiting the antigen in close to $90 \%$ of the population at low fluorescence intensity, but with a good resolution of signal to background was employed. It was selected the minimum antibody concentration required to obtain a positive result. Briefly, the antibody stock solution $(25 \mu \mathrm{g} / \mathrm{mL})$ was first dissolved into CXC dilution buffer (Menarini Silicon Biosystems) to get a ratio of 1:75. Then, for one sample, $30 \mu \mathrm{L}$ of diluted antibody solution was brought to a final volume of 450 $\mu \mathrm{L}$ by addition of the same buffer. Images of PE channel

\section{Merge}
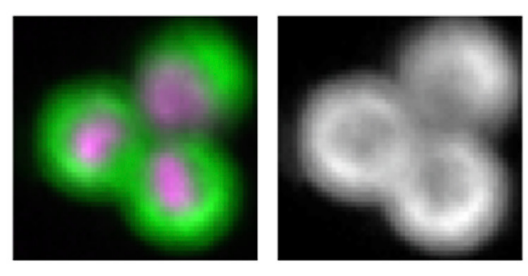

$\alpha \mathbf{C K}$

\section{DAPI}
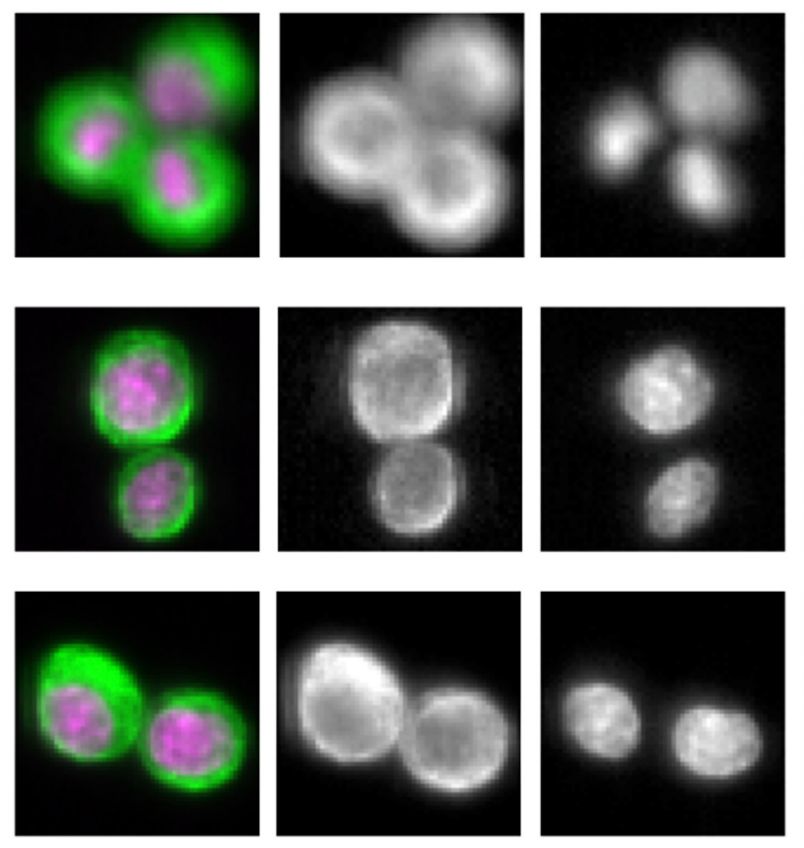

\section{$\alpha$ CD45}
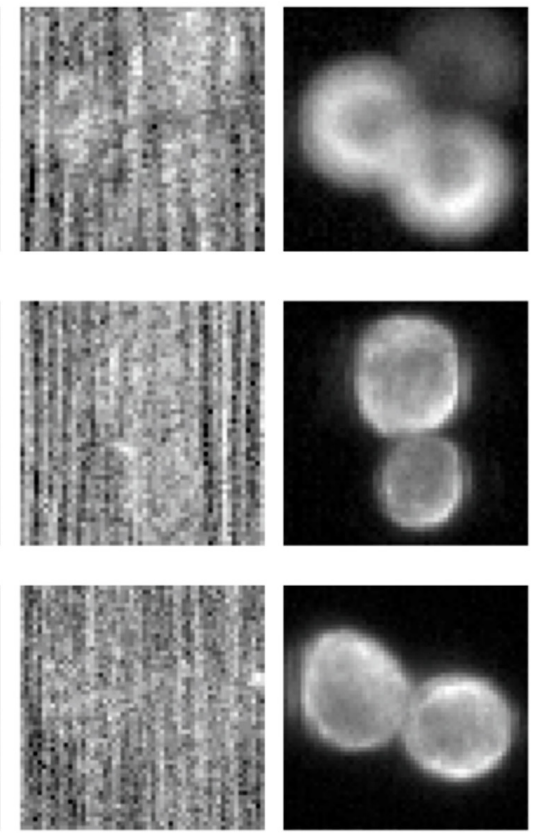
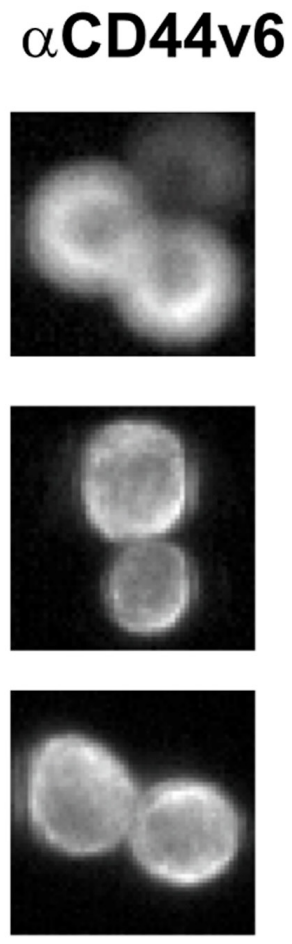

Figure 3: Illustrative images of CD44v6 immunostaining of MDA-MB-231 cell line through CellSearch ${ }^{\circledR}$ system (antibody concentration: $0.02 \mu \mathrm{g} / \mathrm{mL}$; Exposure Time: $0.4 \mathrm{sec}$ ). Abbreviations: CK-FLU, cytokeratin fluorescein-conjugated (green); DAPI, 4',6-diamidino-2-phenylindole (violet); APC, allophycocyanin; PE, phycoerythrin. 
were acquired using an Exposure Time of 0.4 second. A clear image, with a dark background (black or nearly black), was considered as a positive result. Figure 3 shows a positive signal in MDA-MB231 cells without increasing non-specific background.

\section{Statistical analysis}

A sample size of 40 was enrolled as cohort for assessment of CD44v6 status in CTC in mCRC patients undergoing first-line chemotherapy. Based on the presence $(\geq 1)$ or absence of CTC, patients were dichotomized into two categories (positive vs negative). Similarly, in regard to CD44v6 status, a threshold of $\geq$ $1 \mathrm{CTC}$ expressing the antigen was applied to consider a sample as positive. Continuous data were summarized by mean, median and standard deviation. Categorical data were reported by counts and percentages. To assess the difference of age we used Mann-Whitney test. The exact Fisher's test was used to compare the categorical data; the phi index was used to highlight associations between markers and status of disease. The probability level was $p<0.05$. Statistical analysis was performed using STATA v. 12 .

\section{Abbreviations}

5-FU: 5-fluorouracil; APC: allophycocyanin; CK: cytokeratins; CR: complete response; CSC: cancer stem cells; CTC: circulating tumor cells; DAPI: 4',6-diamidino2-phenylindole; EGFR: epidermal growth factor receptor; EMT: epithelial-mesenchymal transition; EpCAM: epithelial cellular adhesion molecule; FLU: fluorescein; MAPK/ERK: mitogen-activated protein kinase/ extracellular-signal-regulated kinase; mCRC: metastatic colorectal cancer; MSI: microsatellite instability; OS: overall survival; PD: progressive disease; PE: Phycoerythrin; PFS: progression-free survival; PR: partial response; RECIST: Response Evaluation Criteria in Solid Tumors; SD: stable disease; VEGF: vascular endothelial growth factor.

\section{Author contributions}

Conceptualization, C.N. and P.G.; methodology, C.N. and R.Z.; validation, C.N., R.Z., A.F. and E.R.; formal analysis, AR.V.; investigation, C.N., F.L., S.C., V.M., A.G., A.F. and E.R.; resources, AR.V., R.Z., E.C. and P.G.; data curation, C.N., F.L., S.C., V.M., A.G., AR.V. and R.Z.; writing-original draft preparation, C.N., AR.V., R.Z., and P.G.; writing-review and editing, C.N. and P.G.; supervision, R.Z., E.C. and P.G.; project administration, E.C. and P.G.; funding acquisition, E.C. and P.G. All authors have read and agreed to the published version of the manuscript.

\section{CONFLICTS OF INTEREST}

The authors declare no conflicts of interest. The funders had no role in the design of the study; in the collection, analyses, or interpretation of data; in the writing of the manuscript, or in the decision to publish the results.

\section{FUNDING}

This work was supported by FO.R.O. onlus.

\section{REFERENCES}

1. Garg M. Epithelial, mesenchymal and hybrid epithelial/ mesenchymal phenotypes and their clinical relevance in cancer metastasis. Expert Rev Mol Med. 2017; 19:e3. https://doi.org/10.1017/erm.2017.6. [PubMed]

2. Agnoletto C, Corrà F, Minotti L, Baldassari F, Crudele F, Cook WJJ, Di Leva G, d'Adamo AP, Gasparini P, Volinia S. Heterogeneity in Circulating Tumor Cells: The Relevance of the Stem-Cell Subset. Cancers (Basel). 2019; 11:483. https://doi.org/10.3390/cancers11040483. [PubMed]

3. Todaro M, Gaggianesi M, Catalano V, Benfante A, Iovino F, Biffoni M, Apuzzo T, Sperduti I, Volpe S, Cocorullo G, Gulotta G, Dieli F, De Maria R, et al. CD44v6 is a marker of constitutive and reprogrammed cancer stem cells driving colon cancer metastasis. Cell Stem Cell. 2014; 14:342-356. https://doi.org/10.1016/j.stem.2014.01.009. [PubMed]

4. Zhou Y, Xia L, Wang H, Oyang L, Su M, Liu Q, Lin J, Tan S, Tian Y, Liao Q, Cao D. Cancer stem cells in progression of colorectal cancer. Oncotarget. 2018; 9:33403-33415. https://doi.org/10.18632/oncotarget.23607. [PubMed]

5. Ma L, Dong L, Chang P. CD44v6 engages in colorectal cancer progression. Cell Death Dis. 2019; 10:30. https:// doi.org/10.1038/s41419-018-1265-7. [PubMed]

6. Li XD, Ji M, Wu J, Jiang JT, Wu CP. Clinical significance of CD44 variants expression in colorectal cancer. Tumori. 2013; 99:88-92. https://doi. org/10.1177/030089161309900115. [PubMed]

7. Sakuma K, Sasaki E, Kimura K, Komori K, Shimizu Y, Yatabe Y, Aoki M. HNRNPLL, a newly identified colorectal cancer metastasis suppressor, modulates alternative splicing of CD44 during epithelial-mesenchymal transition. Gut. 2018; 67:1103-1111. https://doi.org/10.1136/ gutjnl-2016-312927. [PubMed]

8. Amirghofran Z, Jalali SA, Hosseini SV, Vasei M, Sabayan B, Ghaderi A. Evaluation of CD44 and CD44v6 in colorectal carcinoma patients: soluble forms in relation to tumor tissue expression and metastasis. J Gastrointest Cancer. 2008; 39:73-78. https://doi.org/10.1007/s12029009-9062-2. [PubMed]

9. Garouniatis A, Zizi-Sermpetzoglou A, Rizos S, Kostakis A, Nikiteas N, Papavassiliou AG. FAK, CD44v6, c-Met and EGFR in colorectal cancer parameters: tumour progression, 
metastasis, patient survival and receptor crosstalk. Int J Colorectal Dis. 2013; 28:9-18. https://doi.org/10.1007/ s00384-012-1520-9. [PubMed]

10. Lv L, Liu HG, Dong SY, Yang F, Wang QX, Guo GL, Pan YF, Zhang XH. Upregulation of CD44v6 contributes to acquired chemoresistance via the modulation of autophagy in colon cancer SW480 cells. Tumour Biol. 2016; 37:8811-8824. https://doi.org/10.1007/s13277-015-47556. [PubMed]

11. Gazzaniga P, Gradilone A, Petracca A, Nicolazzo C, Raimondi C, Iacovelli R, Naso G, Cortesi E. Molecular markers in circulating tumour cells from metastatic colorectal cancer patients. J Cell Mol Med. 2010; 14:20732077. https://doi.org/10.1111/j.1582-4934.2010.01117.x. [PubMed]

12. Cassidy J, Clarke S, Díaz-Rubio E, Scheithauer W, Figer A, Wong R, Koski S, Lichinitser M, Yang TS, Rivera F, Couture F, Sirzén F, Saltz L. Randomized phase III study of capecitabine plus oxaliplatin compared with fluorouracil/ folinic acid plus oxaliplatin as first-line therapy for metastatic colorectal cancer. J Clin Oncol. 2008; 26:20062012. https://doi.org/10.1200/JCO.2007.14.9898. [PubMed]

13. Van Cutsem E, Köhne CH, Hitre E, Zaluski J, Chang Chien CR, Makhson A, D’Haens G, Pintér T, Lim R, Bodoky G, Roh JK, Folprecht G, Ruff P, et al. Cetuximab and chemotherapy as initial treatment for metastatic colorectal cancer. N Engl J Med. 2009; 360:1408-1417. https://doi. org/10.1056/NEJMoa0805019. [PubMed]

14. Gazzaniga P, Raimondi C, Gradilone A, Biondi Zoccai G, Nicolazzo C, Gandini O, Longo F, Tomao S, Lo Russo G, Seminara P, Vincenzi B, Chimenti I, Cristofanilli M, et al. Circulating tumor cells in metastatic colorectal cancer: do we need an alternative cutoff? J Cancer Res Clin Oncol. 2013; 139:1411-1416. https://doi.org/10.1007/s00432-0131450-0. [PubMed]

15. Fumagalli A, Oost KC, Kester L, Morgner J, Bornes L, Bruens L, Spaargaren L, Azkanaz M, Schelfhorst T, Beerling E, Heinz MC, Postrach D, Seinstra D, et al. Plasticity of Lgr5-Negative Cancer Cells Drives Metastasis in Colorectal Cancer. Cell Stem Cell. 2020; 26:569-578.e7. https://doi.org/10.1016/j.stem.2020.02.008. [PubMed]

16. Soler A, Cayrefourcq L, Mazard T, Babayan A, Lamy PJ, Assou S, Assenat E, Pantel K, Alix-Panabières C. Autologous cell lines from circulating colon cancer cells captured from sequential liquid biopsies as model to study therapy-driven tumor changes. Sci Rep. 2018; 8:15931. https://doi.org/10.1038/s41598-018-34365-z. [PubMed]

17. Grillet F, Bayet E, Villeronce O, Zappia L, Lagerqvist EL, Lunke S, Charafe-Jauffret E, Pham K, Molck C, Rolland N, Bourgaux JF, Prudhomme M, Philippe C, et al. Circulating tumour cells from patients with colorectal cancer have cancer stem cell hallmarks in ex vivo culture. Gut. 2017; 66:1802-1810. https://doi.org/10.1136/gutjnl-2016-311447. [PubMed]

18. Tremmel M, Matzke A, Albrecht I, Laib AM, Olaku V, Ballmer-Hofer K, Christofori G, Héroult M, Augustin HG, Ponta H, Orian-Rousseau V. A CD44v6 peptide reveals a role of CD44 in VEGFR-2 signaling and angiogenesis. Blood. 2009; 114:5236-5244. https://doi.org/10.1182/ blood-2009-04-219204. [PubMed]

19. Mielgo A, van Driel M, Bloem A, Landmann L, Günthert U. A novel antiapoptotic mechanism based on interference of Fas signaling by CD44 variant isoforms. Cell Death Differ. 2006; 13:465-477. https://doi.org/10.1038/sj.cdd.4401763. [PubMed]

20. Rossi E, Basso U, Celadin R, Zilio F, Pucciarelli S, Aieta M, Barile C, Sava T, Bonciarelli G, Tumolo S, Ghiotto C, Magro C, Jirillo A, et al. M30 neoepitope expression in epithelial cancer: quantification of apoptosis in circulating tumor cells by CellSearch analysis. Clin Cancer Res. 2010; 16:5233-5243. https://doi.org/10.1158/1078-0432.CCR-101449. [PubMed]

21. Nicolazzo C, Raimondi C, Mancini M, Caponnetto S, Gradilone A, Gandini O, Mastromartino M, Del Bene G, Prete A, Longo F, Cortesi E, Gazzaniga P. Monitoring PDL1 positive circulating tumor cells in non-small cell lung cancer patients treated with the PD-1 inhibitor Nivolumab. Sci Rep. 2016; 6:31726. https://doi.org/10.1038/srep31726. [PubMed]

22. Nicolazzo C, Gradilone A, Carpino G, Gazzaniga P, Raimondi C. Molecular Characterization of Circulating Tumor Cells to Study Cancer Immunoevasion. Methods Mol Biol. 2019; 1884:247-258. https://doi.org/10.1007/9781-4939-8885-3 17. [PubMed]

23. Pantano F, Rossi E, Iuliani M, Facchinetti A, Simonetti S, Ribelli G, Zoccoli A, Vincenzi B, Tonini G, Zamarchi $\mathrm{R}$, Santini D. Dynamic changes of Receptor activator of nuclear factor-kappaB expression in Circulating Tumor Cells during Denosumab predict treatment effectiveness in Metastatic Breast Cancer. Sci Rep. 2020; 10:1288. https:// doi.org/10.1038/s41598-020-58339-2. [PubMed]

24. Gennari A, Foca F, Zamarchi R, Rocca A, Amadori D, De Censi A, Bologna A, Cavanna L, Gianni L, Scaltriti L, Rossi E, Facchinetti A, Martini V, et al. Insulin-like growth factor-1 receptor (IGF-1R) expression on circulating tumor cells (CTCs) and metastatic breast cancer outcome: results from the TransMYME trial. Breast Cancer Res Treat. 2020; 181:61-68. https://doi.org/10.1007/s10549-020-05596-4. [PubMed] 